\title{
Systematic analysis of three FHM genes in 39 sporadic patients with hemiplegic migraine
}

B. de Vries, MSc*

T. Freilinger, MD*

K.R.J. Vanmolkot, $\mathrm{MSc}$

J.B. Koenderink, PhD

A.H. Stam, MD

G.M. Terwindt, MD, $\mathrm{PhD}$

E. Babini, $\mathrm{PhD}$

E.H. van den Boogerd, BSc

J.J.M.W. van den Heuvel, BSc

R.R. Frants, PhD

J. Haan, MD, PhD

M. Pusch, PhD

A.M.J.M. van den Maagdenberg, PhD

M.D. Ferrari, MD, $\mathrm{PhD}$

M. Dichgans, MD, $\mathrm{PhD}$

Address correspondence and reprint requests to Dr. Michel D. Ferrari, Department of Neurology, Leiden University Medical Centre, PO Box 9600, 2300 RC Leiden, The Netherlands m.d.ferrari@lumc.nl

Supplemental data at www.neurology.org

\section{ABSTRACT}

Background: Familial (FHM) and sporadic (SHM) hemiplegic migraine are severe subtypes of migraine associated with transient hemiparesis. For FHM, three genes have been identified encoding subunits of a calcium channel (CACNA1A), a sodium-potassium pump (ATP1A2), and a sodium channel (SCN1A). Their role in SHM is unknown. Establishing a genetic basis for SHM may further the understanding of its pathophysiology and relationship with common types of migraine. It will also facilitate the often difficult differential diagnosis from other causes of transient hemiparesis.

Methods: We systematically scanned 39 well-characterized patients with SHM without associated neurologic features for mutations in the three FHM genes. Functional assays were performed for all new sequence variants.

Results: Sequence variants were identified in seven SHM patients: one CACNA1A mutation, five ATP1A2 mutations, and one SCN1A polymorphism. All six mutations caused functional changes in cellular assays. One SHM patient later changed to FHM because another family member developed FHM attacks.

Conclusion: We show that FHM genes are involved in at least a proportion of SHM patients without associated neurologic symptoms. Screening of ATP1A2 offers the highest likelihood of success. Because FHM gene mutations were also found in family members with "nonhemiplegic" typical migraine with and without aura, our findings reinforce the hypothesis that FHM, SHM, and "normal" migraine are part of a disease spectrum with shared pathogenetic mechanisms. Neurology ${ }^{\circledR}$ 2007;69:2170-2176

\section{GLOSSARY}

ATPase $=$ adenosine triphosphatase; $\mathbf{B A M}=$ basilar artery migraine; $\mathbf{C t r l}=$ control; $\mathbf{c D N A}=$ complementary DNA; Fam = family; $\mathbf{F H M}=$ familial hemiplegic migraine; $\mathbf{H M}=$ hemiplegic migraine; IHS = International Headache Society; $\mathbf{M A}=$ migraine with aura; $\mathbf{M O}=$ migraine without aura; $\mathbf{S H M}=$ sporadic hemiplegic migraine; $\mathbf{W T}=$ wild type.

Hemiplegic migraine is a rare, often severe subtype of migraine with aura in which attacks are associated with hemiparesis. ${ }^{1}$ Otherwise, the aura and headache symptoms are identical to those of common types of migraine. ${ }^{2}$ Hemiplegic migraine may run in families (familial hemiplegic migraine [FHM]) or may be sporadic (SHM). ${ }^{1}$ Clinically, FHM and SHM attacks are indistinguishable, and the majority of patients also have common attacks of migraine with or without aura, not associated with hemiparesis. ${ }^{3}$

Thus far, three genes for FHM have been identified. The CACNA1A gene (FHM1) ${ }^{4}$ encoding the pore-forming subunit $\mathrm{Ca}_{\mathrm{v}} 2.1$ of neuronal $\mathrm{P} / \mathrm{Q}$-type calcium channels, the

*These authors contributed equally.

From the Departments of Human Genetics (B.d.V., K.R.J.V., E.H.v.d.B., R.R.F., A.M.J.M.v.d.M.) and Neurology (A.H.S., G.M.T., J.H., A.M.J.M.v.d.M., M.D.F.), Leiden University Medical Centre, Leiden, The Netherlands; Department of Neurology, Klinikum Großhadern, Ludwig-Maximilians-Universität, München, Germany (T.F., M.D.); Department of Pharmacology and Toxicology, Centre for Molecular Life Sciences, University Medical Centre St. Radboud, Nijmegen, The Netherlands (J.B.K., J.J.M.W.v.d.H.); Istituto di Biofisica, Consiglio Nazionale delle Ricerche, Genoa, Italy (E.B., M.P.); and Department of Neurology, Rijnland Hospital, Leiderdorp, The Netherlands (J.H.). Supported by grants from The Netherlands Organization for Scientific Research (903-52-291, M.D.F., R.R.F., and Vici 918.56.602, M.D.F.), The Migraine Trust, (R.R.F., M.D.F.), the EU “EUROHEAD” grant (LSHM-CT-2004-504837, M.D.F., R.R.F., A.M.J.M.v.d.M), Hersenstichting (J.B.K., A.M.J.M.v.d.M.), and the Center of Medical System Biology established by The Netherlands Genomics Initiative/ Netherlands Organization for Scientific Research. Further supported by the Deutsche Forschungsgemeinschaft (DFG D1 722/8-1 and DI 722/ 8-2) and Telethon Italy (grant GGP04018).

Disclosure: The authors report no conflicts of interest. 
ATP1A2 gene $(\mathrm{FHM} 2)^{5}$ encoding the $\alpha 2$ subunit of sodium-potassium pumps, and the SCN1A gene (FHM3) encoding the $\alpha 1$ subunit of neuronal sodium channels.

Although clinically indistinguishable, ${ }^{3}$ it is unknown whether and to what extent SHM and FHM are pathophysiologically related and whether and to what extent FHM genes are also involved in SHM. Previous studies identified mutations in the CACNA1A gene in SHM patients..$^{711}$ Most of these patients showed cerebellar signs, suggesting an involvement of the CACNA1A gene in SHM with associated cerebellar and other neurologic signs or symptoms, such as cerebral edema and coma after minor head trauma. In contrast, the role of the FHM genes in "pure" SHM without associated neurologic symptoms is less clear. One CACNA1A mutation $(\mathrm{R} 583 \mathrm{Q})^{8}$ and one ATP1A2 mutation $(\mathrm{R} 383 \mathrm{H})^{12}$ were reported in such patients.

Investigating the involvement of FHM genes in sporadic patients with hemiplegic migraine is important because it may further the insight into the pathophysiology of SHM and the relationship with other types of migraine. Moreover, understanding and establishing the genetic basis of SHM may help clinicians in diagnostic and therapeutic decision making. Many patients are initially misdiagnosed and mistreated. We therefore set out to search systematically for mutations in the known FHM genes in a large set of 39 clinically well-characterized patients with "pure" SHM, who had no interictal neurologic symptoms.

METHODS Patients. Sporadic hemiplegic migraine was diagnosed according to the criteria of the International Headache Society (IHS). ${ }^{1}$ Patients with interictal neurologic symptoms, in particular ataxia, were excluded because these patients have a high a priori probability of carrying a CACNA1A mutation. ${ }^{7-11}$ All available family members were directly interviewed, and their headache was diagnosed according to the IHS criteria. In addition to newly recruited SHM patients, we included 25 of the 27 patients from our previous study in which only the FHM1 CACNA1A gene was investigated. ${ }^{8}$ Two patients from that study were excluded because of associated symptoms; one had ataxia and carried the T666M mutation, the other patient had childhood epilepsy and did not carry a CACNA1A mutation. Approval was obtained by local ethical committees in accordance with national legislation; all patients gave informed consent.
Mutation scanning. Genomic DNA was isolated from peripheral leukocytes using a standard salting out extraction method. The CACNA1A, ATP1A2, and SCN1A genes were screened for mutations by sequencing. ${ }^{6,8,13}$ In brief, all exons and flanking intronic regions were amplified by PCR, using genomic DNA as a template. Direct sequencing was performed with Cycle Sequencing (Prism Big Dye Terminators Cycle Sequencing kit, Applied Biosystems, Foster City, CA) using the dideoxy termination method and an ABI3700 automated sequencer (Applied Biosystems). For each exonic variant identified, 150 healthy controls were screened, by restriction enzyme analysis or direct sequencing. Detailed information is available from the authors on request.

Functional analysis. Functional analysis of mutations in the $\mathrm{Ca}_{\mathrm{v}} 2.1-\alpha_{1}$ calcium channel subunit was not performed because the single CACNA1A mutation found in this study was thoroughly investigated before. ${ }^{14}$ Functional analysis of ATP1A2 variants was performed by survival assays. Human $\mathrm{Na}, \mathrm{K}$-adenosine triphosphatase (ATPase) $\alpha_{2}$-subunit complementary DNA (cDNA) was subcloned into a modified pCDNA3.1 vector. ${ }^{15}$ To distinguish endogenous $\mathrm{Na}, \mathrm{K}$ ATPase activity from that of transfected $\mathrm{Na}, \mathrm{K}-\mathrm{ATP}$ ase, we used a cDNA construct encoding ouabain-resistant wildtype (ATP1A2-WT). ${ }^{15,16}$ Mutations E120A, E492K, P786L, R834X, and R908Q were introduced in the ouabain-resistant wild-type $\alpha_{2}$-subunit construct by site-directed mutagenesis (Quikchange, Stratagene, La Jolla, CA). HeLa cells $\left(5 \times 10^{5}\right)$ were transfected with plasmid DNA of either ATP1A2-WT or ATP1A2-mutant (ATP1A2-E120A, ATP1A2-E492K, ATP1A2-P789L, ATP1A2-R834X, ATP1A2-R908Q) using Lipofectamine 2000 Transfection Reagent (Invitrogen, Carlsbad, CA). Two days after transfection, two-thirds of the cells were harvested for immunoblotting, and the $\alpha_{2^{-}}$ subunit protein was detected using the specific polyclonal antibody HERED. ${ }^{15,16}$ The remaining one-third of the cells was seeded on $10-\mathrm{cm}$ petri dishes, and subsequently $1 \mu \mathrm{M}$ ouabain was added to the culture medium. After 5 days of ouabain challenge, colonies were stained with $1 \%$ methylene blue in $70 \%$ methanol, scanned, and analyzed with Image Pro Plus (MediaCybernetics, Silver Spring, MD). Each transfection was performed 7 to 15 times. In case of partial survival, statistical significance was tested using Student $t$ test $(p<0.05)$.

For functional analysis of the SCN1A variant, we used the closely related $S C N 5 A$ cDNA, because of the known stability problems of recombinant bacteria with SCN1A cDNA. ${ }^{6,17}$ R1914G, which corresponds to SCN1A R1928G, was introduced by site-directed mutagenesis into full-length human SCN5A cDNA subcloned in pCDNA3.1 (QuikChange XL Kit, Stratagene). SCN5A-R1914G and SCN5A-WT cDNAs were transfected into human tsA201 cells and were each coexpressed with accessory human sodium channel subunit $\beta_{1}{ }^{6}$ Macroscopic sodium currents were recorded using the whole-cell configuration of the patch clamp technique. ${ }^{6}$ Steady state activation, steady state inactivation, time constants of inactivation (e.g., time constants $\tau_{\mathrm{fh}}$ and $\tau_{\mathrm{sh}}$ ), and recovery from inactivation (e.g., $\tau_{\mathrm{fast}}$ and $\tau_{\text {slow }}$ time constants) were measured using protocols, as described before. ${ }^{6}$

RESULTS Patients. Thirty-nine patients with "pure" SHM were included; 37 originated from Western Europe (mostly The Netherlands or Ger- 
Table 1 Clinical and genetic characteristics of SHM patients

\begin{tabular}{|c|c|c|c|c|c|c|c|c|c|}
\hline Patient & $\begin{array}{l}\text { Mutation in } \\
\text { HM gene }\end{array}$ & $\begin{array}{l}\text { Age at } \\
\text { onset, } y\end{array}$ & $\begin{array}{l}\text { Frequency } \\
\text { of attacks, } \\
\text { per y }\end{array}$ & $\begin{array}{l}\text { Total } \\
\text { duration } \\
\text { of attack }\end{array}$ & $\begin{array}{l}\text { Duration of } \\
\text { paresis }\end{array}$ & $\begin{array}{l}\text { BAM } \\
\text { symptoms }\end{array}$ & $\begin{array}{l}\text { Unconsciousness } \\
\text { during attacks }\end{array}$ & $\begin{array}{l}\text { Attacks } \\
\text { triggered } \\
\text { by minor } \\
\text { head trauma }\end{array}$ & $\begin{array}{l}\text { MO or MA in } \\
\text { first-degree } \\
\text { family members }\end{array}$ \\
\hline 1 & No & 27 & 3 & $1-2 d$ & Minutes & No & No & No & MO \\
\hline 2 & No & 20 & 4 & $4 h-2 d$ & $0.5-2 \mathrm{~h}$ & No & No & No & MA \\
\hline 3 & No & 12 & $?$ & Days & Hours & No & No & No & MA \\
\hline 4 & No & 18 & 24 & $15-60 \mathrm{~min}$ & $15 \min$ & No & No & No & MO \\
\hline 5 & No & 20 & $0-3$ & $8 \mathrm{~h}$ & $1 \mathrm{~h}$ & No & No & No & No \\
\hline 6 & ATP1A2- R834X & 10 & 1 & $4 d$ & $2 d$ & No & No & Yes & MO \\
\hline 7 & No & 22 & 12 & $12 \mathrm{~h}$ & $0.5-2 \mathrm{~h}$ & No & No & No & $\mathrm{MO}$ and $\mathrm{MA}$ \\
\hline 8 & No & 9 & $12-30$ & $1-3 d$ & $1 \mathrm{~h}-1 \mathrm{~d}$ & No & No & No & MA \\
\hline 9 & No & 25 & 24 & Hours-3 d & $0.5-1 \mathrm{~h}$ & Yes & No & No & MO \\
\hline 10 & No & 12 & $4-36$ & $1-2 d$ & $5-10 \mathrm{~min}$ & No & Yes & No & No \\
\hline 11 & No & 19 & 2 in lifetime & 20 min-1 h & $20 \min$ & No & No & No & MA \\
\hline 12 & ATP1A2-E120A & 13 & $12-250$ & $1 d$ & $1 \mathrm{~h}$ & No & No & No & No \\
\hline 13 & No & 25 & 48 & $10-24 \mathrm{~h}$ & $?$ & $?$ & No & No & $\mathrm{MO}$ and $\mathrm{MA}$ \\
\hline 14 & No & 13 & $2-6$ & Few hours & $0.5 \mathrm{~h}$ & No & No & No & $\mathrm{MO}$ and $\mathrm{MA}$ \\
\hline 15 & No & 29 & $2-100$ & Minutes-hours & Minutes-hours & Yes & Yes & Yes & No \\
\hline 16 & No & 4 & 24 & $1 d$ & Few hours & Yes & No & No & MA \\
\hline 17 & No & 10 & Once & $1 d$ & $1 \mathrm{~h}$ & No & No & No & $\mathrm{MO}$ and $\mathrm{MA}$ \\
\hline 18 & No & 20 & $0-2$ & $1 \mathrm{wk}-1 \mathrm{mo}$ & 1 wk-1 mo & $?$ & No & No & MO \\
\hline 19 & ATP1A2-P786L & 5 & 0.5 & $3 w k$ & $6 d$ & No & No & No & No \\
\hline 20 & No & 16 & 12 & $1 d$ & $1 \mathrm{~h}$ & No & No & No & $\mathrm{MO}$ and $\mathrm{MA}$ \\
\hline 21 & No & 13 & Once & Few days & Few days & No & No & No & $\mathrm{MO}$ and $\mathrm{MA}$ \\
\hline 22 & No & 13 & $2-52$ & $1 d$ & $0.5-1 \mathrm{~h}$ & No & No & No & No \\
\hline 23 & ATP1A2-E492K & 19 & 2 & $?$ & $?$ & No & No & No & MA \\
\hline 24 & No & 32 & $2-12$ & Days & Hours-days & No & No & No & No \\
\hline 25 & CACNA1A-R583Q & 13 & 2 & $1 d$ & $0.5 \mathrm{~h}$ & No & No & No & MA \\
\hline 26 & No & 34 & 8 & $0.5 ?$ & Hours? & No & No & No & No \\
\hline 27 & No & 37 & $36-48$ & 3-48 h? & Hours-48h & No & No & No & $\mathrm{MO}$ or MA? \\
\hline 28 & SCN1A-R1928G & 38 & 2 in lifetime & Few hours & $1.5 \mathrm{~h}$ & No & Yes & No & $\mathrm{MO}$ and $\mathrm{MA}$ \\
\hline 29 & No & 42 & 2 in lifetime & $3-4$ hours & $0.5 \mathrm{~h}$ & No & No & No & Migraine unspecified \\
\hline 30 & No & 11 & 30 in lifetime & Hours & $1 \mathrm{~h}$ & No & No & No & $\begin{array}{l}\text { MA and migraine } \\
\text { unspecified }\end{array}$ \\
\hline 31 & No & 17 & 24 & Up to $4 \mathrm{~h}$ & $3-4 h$ & No & No & No & MA in grandmother \\
\hline 32 & No & 22 & up to 50 & Hours & Hours & No & No & No & No \\
\hline 33 & No & 15 & 4 to 10 & $1 \mathrm{~h}$ & $15-30 \mathrm{~min}$ & No & No & No & Migraine unspecified \\
\hline 34 & ATP1A2-R908Q & 5 & 2 to 5 & $2 \mathrm{~h}$ & $30-90 \mathrm{~min}$ & Yes & No & No & No \\
\hline 35 & No & 27 & 5 in lifetime & Up to $7 \mathrm{~h}$ & Up to $7 \mathrm{~h}$ & No & No & No & $\mathrm{MO}$ and $\mathrm{MA}$ \\
\hline 36 & No & 16 & 4 & $1.5-3 \mathrm{~h}$ & $1-3 h$ & No & No & No & No \\
\hline 37 & No & 4 & 4 & Hours & $24-72 h$ & No & No & No & No \\
\hline 38 & No & 8 & $2-12$ & Hours & $15-60 \mathrm{~min}$ & No & No & No & No \\
\hline 39 & No & 35 & 5 & Few hours & $15 \mathrm{~min}-3 \mathrm{~h}$ & No & Yes & No & MA \\
\hline
\end{tabular}

$\mathrm{SHM}=$ sporadic hemiplegic migraine; $\mathrm{HM}=$ hemiplegic migraine; $\mathrm{BAM}=$ basilar artery migraine; $\mathrm{MO}=$ migraine without aura; $\mathrm{MA}=$ migraine with aura.

many) and 2 came from the United States (table 1). As expected, ${ }^{3,18}$ some of the patients exhibited basilar-type migraine symptoms during the attacks, but they were all free of interictal signs or symptoms. Age at onset of hemiplegic attacks ranged from 4 to 42 years. The number of attacks varied from 2 per lifetime to more than 200 per year. Likewise, duration of hemiparesis was variable, from several minutes to 1 week. Four patients reported loss of consciousness during 


\begin{tabular}{|llll|}
\hline Table 2 & \multicolumn{2}{l}{ DNA variants identified in pure SHM patients } \\
Gene & Amino acid change & Nucleotide change & Abnormality in functional test \\
CACNA1A & R583Q & nt2021G $>$ A & Electrophysiologicconsequence \\
ATP1A2 & E120A & nt 463A $>C$ & Partial cell survival \\
ATP1A2 & E492K & nt 1578G $>$ A & Partial cell survival \\
ATP1A2 & P786L & nt 2604C $>$ T & No cell survival \\
ATP1A2 & R834X & nt 2461C $>$ T & No cell survival \\
ATP1A2 & R908Q & nt 2827G $>$ A & No cell survival \\
SCN1A & R1928G & nt 5782C $>$ G & No electrophysiologic consequence
\end{tabular}

$\mathrm{SHM}=$ sporadic hemiplegic migraine.

attacks; 2 patients reported triggering of attacks by minor head trauma. In 1 patient, the initial diagnosis was later changed to FHM, when a family member developed hemiplegic migraine attacks. Notwithstanding, this patient was kept in the SHM group because he fulfilled the inclusion criteria of SHM at the time of clinical presentation. In approximately $70 \%$ of the families of our 39 SHM patients, attacks of common nonhemiplegic migraine with aura (one-third), without aura (one-third), or both (one-third) were present in one or more first-degree relatives.

Genetic and functional findings. Sequencing of all exons and flanking intronic sequences in the 39 index cases revealed seven different sequence variants which were present in seven probands (table 2 and figure 1): one in CACNA1A, five in $A T P 1 A 2$, and one the SCN1A gene. None of the sequence variants was present in 150 healthy controls (data not shown).

CACNA1A. The single variant in the CACNA1A gene (R583Q) has been reported as part of our earlier study. ${ }^{8} \mathrm{R} 583 \mathrm{Q}$ was present in the index case and his unaffected mother, who had migraine with aura but no hemiplegic attacks indicating incomplete penetrance. R583Q has previously been identified in families with FHM and shown to affect $\mathrm{Ca}_{\mathrm{v}} 2.1 \mathrm{Ca}^{2+}$ channel gating in functional studies. ${ }^{14}$ Thus, R583Q can be considered causative in our case.

ATP1A2. The five DNA variants in ATP1A2 included four missense variants (E120A, E492K, P786L, R908Q) and one nonsense mutation (R834X). P786, R908, and R834 are completely

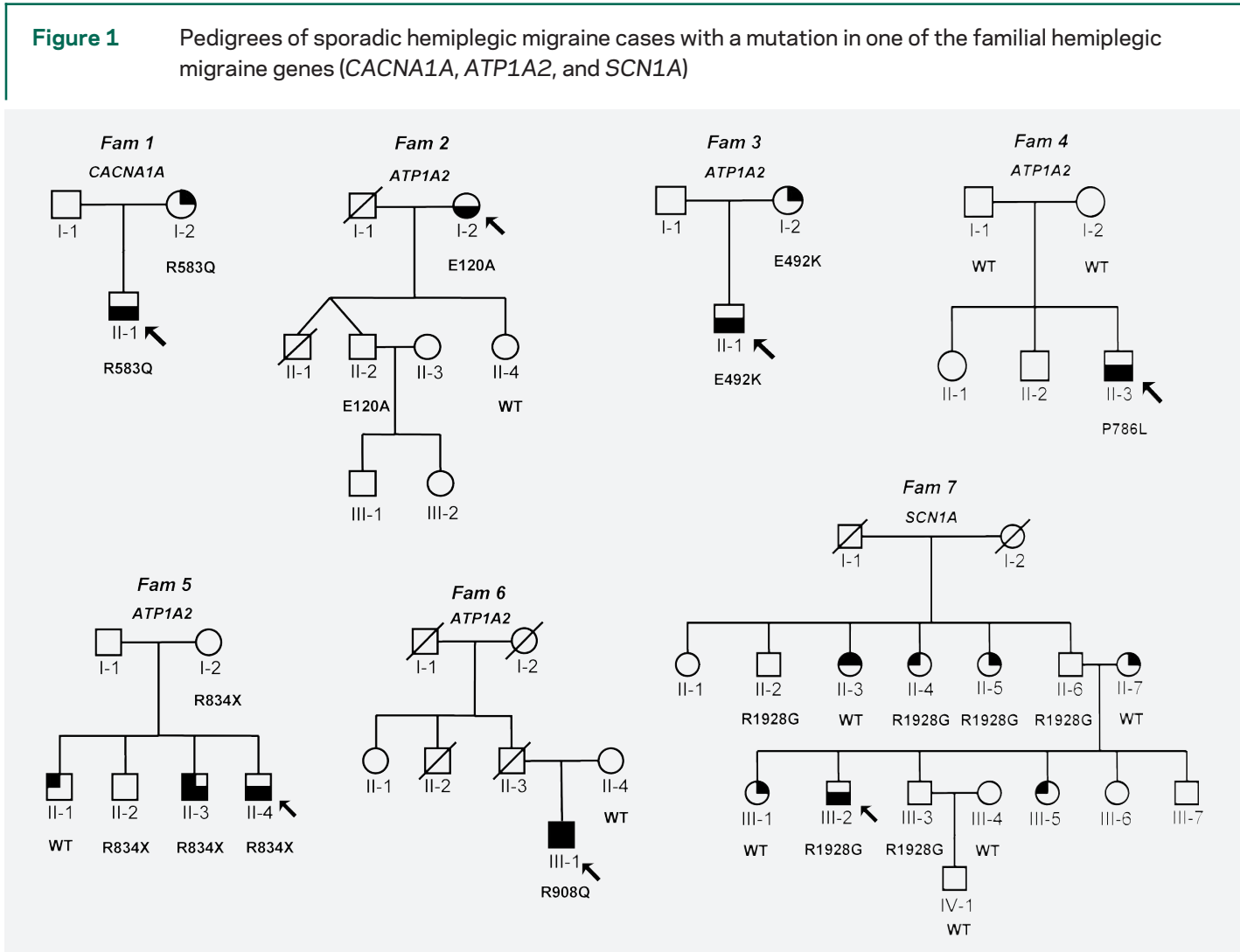

The following symbols are used to indicate the diagnosis: filled lower half = familial hemiplegic migraine; right upper quadrant $=$ migraine with aura; left upper quadrant $=$ migraine without aura. Circle $=$ female; square $=$ male. Arrows indicate probands. Individuals homozygous for the wild-type allele are indicated by WT; individuals heterozygous for a DNA variant are indicated by the respective variant. Fam = family. 


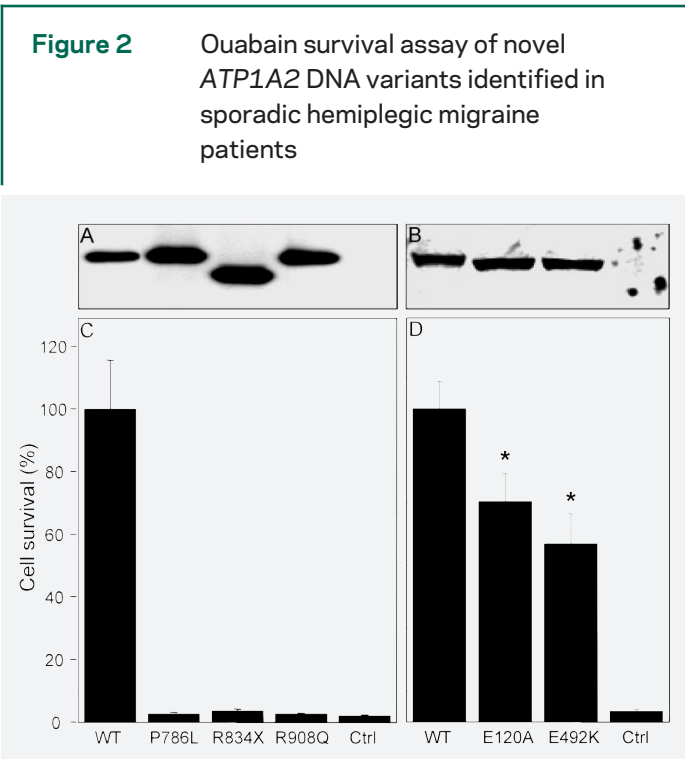

(A and B) Western blot analysis of HeLa cells transfected with wild-type (WT) or mutant ATP1A2 complementary DNA (cDNA). (C and D) Ouabain sensitivity of cells transfected with either wild-type or mutant ATP1A2 cDNA. Bars represent cell survival after 5 days of ouabain treatment (error bars $=\mathrm{SEM})$. ${ }^{*}$ Partial survival is significantly lower than for WT ( $p<0.05)$. Mutants P786L, R834X, and R908Q gave no survival. $\mathrm{Ctrl}=$ control.

conserved across multiple homologs and orthologs, whereas E120 and E492 are less well conserved (figure E-1 on the Neurology ${ }^{\circledR}$ Web site at www.neurology.org). The P786L mutation was not present in the proband's parents. False paternity was excluded in this case. Thus, P786L represents a de novo mutation. E120A, E492K, and $\mathrm{R} 834 \mathrm{X}$ were all present in one or more relatives who had no hemiplegic attacks, thus suggesting incomplete penetrance. R908Q was not present in the proband's mother, but DNA from additional family members was not available (figure 1).

Functional consequences of all five ATP1A2 variants were investigated using survival assays in HeLa cells as previously reported for FHM2 mutations. ${ }^{5,16}$ The survival assays test for the ability of mutant protein to compensate for the loss of endogenous $\mathrm{Na}, \mathrm{K}$ pump function, as achieved by ouabain treatment (figure 2, C and D). Because of an altered ouabain binding site, the transfected wild-type (ATP1A2-WT) and mutant (ATP1A2-E120A, ATP1A2-E492K, ATP1A2-P786L, ATP1A2-R834X, ATP1A2-R908Q) Na,K-ATPase $\alpha_{2}$ subunits are ouabain insensitive. Western blot analysis showed that the constructs were expressed at comparable levels (figure 2, A and B). In the survival assay, cells expressing the wild-type construct survived ouabain treatment. In contrast, ATP1A2 mutants gave no (ATP1A2-P786L, ATP1A2-R834X, ATP1A2$R 908 Q$ ) or partial (ATP1A2-E120A $[p=0.03]$,
ATP1A2-E492K $[p=0.002])$ cell survival, indicating a clear functional consequence for all mutants (figure 2, C and D).

SCN1A. DNA variant R1928G in the SCN1A gene was present in the index case and five additional family members, two of whom had nonhemiplegic migraine. R1914G (which is equivalent to SCN1A-R1928G) was introduced to highly homologous human SCN5A (SCN5A$R 1914 G$ ) and functionally tested for its biophysical properties by patch clamp experiments in transiently transfected human tsA201 cells. ${ }^{6}$ Cells expressing the SCN5A-R1914G showed no significant difference in current density, steady state activation, steady state inactivation, and recovery from inactivation when compared with wild type (table E-1). These results indicate that the variant may be a DNA variant without a biologically significant effect on $\mathrm{Na}_{\mathrm{v}} 1.1$ channel functioning.

DISCUSSION We screened 39 patients with "pure" SHM without ataxia or other additional neurologic features for mutations in the three known FHM genes. In 7 patients, we found a sequence variant (table 2). None was found in 300 control chromosomes. Six of these showed obvious functional changes and can be considered causal mutations. These results indicate that genes for FHM are involved in at least a proportion of patients with "pure" SHM. Our findings have important pathogenetic, clinical, and diagnostic implications.

With our findings, a sensible approach to genetic testing in SHM has become available to confirm the often difficult and clinically important diagnosis of SHM..$^{19}$ Because SHM patients with de novo mutations may represent the founder of a new family with highly disabling FHM, genetic confirmation of the diagnosis may have consequences for genetic counseling. When genetic testing is considered in a patient with "pure" SHM, the ATP1A2 gene should be screened first. We found an ATP1A2 sequence variant in five of the seven SHM cases with a confirmed sequence variant corresponding to $13 \%$ of the overall SHM sample. This is a strikingly higher prevalence compared with a previous study of the ATP1A2 gene that included patients with SHM but provided no specific clinical details. ${ }^{12}$

Our findings are in line with earlier smaller studies showing that the yield of CACNA1A mutations in SHM patients is low in the absence of ataxia..$^{20,21}$ In contrast, CACNA1A mutations were found in $50 \%$ of SHM patients with associated cerebellar signs. ${ }^{79}$ The present study is the 
first to evaluate the role of the recently identified FHM3 gene ${ }^{6}$ in SHM. The likelihood of finding SCN1A mutations in "pure" SHM, however, seems very low.

Most ATP1A2 mutations in this study were also found in asymptomatic relatives and in relatives with nonhemiplegic migraine. They thus showed reduced penetrance, as has also been noticed for ATP1A2 mutations associated with FHM2. ${ }^{22-24}$ This might explain why mutations in the ATP1A2 gene are relatively common among sporadic patients. In contrast, all SCN1A mutations previously identified in FHM families showed complete penetrance. ${ }^{6,17}$ This might relate to the low yield of mutations in this gene in our sample of sporadic cases.

Although we found FHM gene mutations in $18 \%$ of our patients with pure SHM, we did not find mutations in the majority of our patients. It is likely that when additional genes for FHM are discovered, greater proportions of patients with SHM will prove to have mutations in FHM genes. Until then, a diagnosis of SHM remains based on the exclusion of other causes of recurrent hemiparesis, careful physical examination, detailed personal and family history, and regular follow-up. In one patient (with ATP1A2 mutation R834X; Family 5: figure 1), we had to change the initial diagnosis of SHM to FHM when an additional family member developed hemiplegic migraine attacks several years after our initial investigation. A diagnosis of pure SHM is likely when transient hemiparesis occurs in the course of a typical attack of migraine with aura, when there are no interictal abnormalities, and when "normal" attacks of migraine with or without aura are present in first-degree relatives. ${ }^{25}$ Approximately $70 \%$ of pure SHM cases and $60 \%$ of the mutation carriers had first-degree relatives with common types of migraine.

Our findings provide genetic evidence that FHM genes are also involved in SHM and thus extend and reinforce the growing clinical, epidemiologic, genetic, and pathophysiologic evidence that FHM and SHM share neurobiological mechanisms. ${ }^{26}$ Moreover, because the majority of hemiplegic migraine patients also have "normal" attacks of migraine without hemiparesis, both diseases can be considered extremes of the pathogenetic migraine spectrum with shared common pathways with "normal" migraine with and without aura. ${ }^{26-29}$

We identified five sequence variants in ATP1A2 (figure 1; Families 2 through 6). All conferred reduced survival in cellular assays (figure 2) and therefore are likely to be causative mutations. P786L occurred de novo and could thus be the founder of a new FHM family. R908Q was found in a patient whose mother did not carry the mutation. Because DNA from the father was not available, it could not be established whether the mutation had occurred de novo. E120A and E492K showed partially reduced survival (figure 2D). Both mutations were identified in other family members who were unaffected or had nonhemiplegic migraine with aura. The single CACNA1A mutation (R583Q) we found was previously shown to affect $\mathrm{Ca}_{\mathrm{v}} 2.1 \mathrm{Ca}^{2+}$ currents in cellular models by changing channel gating. ${ }^{14}$ The mutation was inherited from the mother, who has attacks of nonhemiplegic migraine with aura. The R1928G DNA variant that was identified in the SCN1A gene did not reveal significant effects on channel properties as investigated by electrophysiologic recordings. Also, this variant poorly segregates with the migraine phenotype. It was present in five nonhemiplegic family members; only one of them has migraine with aura, and another has migraine without aura. R1928G may therefore be a rare sequence variant without functional consequences.

Screening of FHM genes in sporadic patients with hemiplegic migraine may help to establish the diagnosis, enable counseling, and prevent unnecessary diagnostic and therapeutic trial with potentially harmful drugs. Scanning of the FHM2 ATP1A2 gene seems to offer the highest likelihood of success. Because FHM mutations were also found in SHM and common types of migraine with or without aura, our findings reinforce the growing evidence that FHM, SHM, basilar-type migraine, and "normal" migraine are part of a disease spectrum with at least some shared pathogenetic pathways. Unraveling these pathways may help to identify novel migraine prophylactic drugs.

\section{ACKNOWLEDGMENT}

The authors thank Dr. Thomas A. Pressley (The University of Texas Medical School, Lubbock, TX) for providing anti-HERED antibody; L. Bouti, L. Broos, and B. Stunnenberg for their technical assistance; and Prof. Dr. Thomas Friedrich (Technische Universität Berlin) for providing the ATP1A2-R908Q cDNA.

Received March 30, 2007. Accepted in final form May 31, 2007.

\section{REFERENCES}

1. Headache Classification Subcommittee of the International Headache Society. The international classification of headache disorders: 2nd edition. Cephalalgia 2004;24:1-160

2. Ferrari MD. Migraine. Lancet 1998;351:1043-1451. 
3. Thomsen LL, Ostergaard E, Olesen J, Russell MB. Evidence for a separate type of migraine with aura: sporadic hemiplegic migraine. Neurology 2003;60:595601.

4. Ophoff RA, Terwindt GM, Vergouwe MN, et al. Familial hemiplegic migraine and episodic ataxia type-2 are caused by mutations in the $\mathrm{Ca} 2+$ channel gene CACNL1A4. Cell 1996;87:543-552.

5. De Fusco M, Marconi R, Silverstri L, et al. Haploinsufficiency of ATP1A2 encoding the $\mathrm{Na}+/ \mathrm{K}+$ pump alpha2 subunit associated with familial hemiplegic migraine type 2. Nat Genet 2003;33:192-196.

6. Dichgans M, Freilinger T, Eckstein G, et al. Mutation in the neuronal voltage-gated sodium channel SCN1A in familial hemiplegic migraine. Lancet 2005;336:371377.

7. Ducros A, Denier C, Joutel A, et al. The clinical spectrum of familial hemiplegic migraine associated with mutations in a neuronal calcium channel. N Engl J Med 2001;345:17-24.

8. Terwindt G, Kors E, Haan J, et al. Mutation analysis of the CACNA1A calcium channel subunit gene in 27 patients with sporadic hemiplegic migraine. Arch Neurol 2002;59:1016-1018.

9. Ducros A, Denier C, Joutel A, et al. Recurrence of the T666M calcium channel CACNA1A gene mutation in familial hemiplegic migraine with progressive cerebellar ataxia. Am J Hum Genet 1999;64:89-98.

10. Vahedi K, Dernier C, Ducros A, et al. CACNA1A gene de novo mutation causing hemiplegic migraine, coma, and cerebellar atrophy. Neurology 2000;55:1040-1042.

11. Curtain RP, Smith RL, Ovcaric M, Griffiths LR. Minor head trauma-induced sporadic hemiplegic coma. Pediatr Neurol 2006;34:329-332.

12. Jurkat-Rott K, Freilinger T, Dreier JP, et al. Variability of familial hemiplegic migraine with novel A1A2 $\mathrm{Na}^{+} /$ $\mathrm{K}^{+}$-ATPase variants. Neurology 2004;62:1857-1861.

13. Vanmolkot KRJ, Kors EE, Hottenga JJ, et al. Novel mutations in the $\mathrm{Na}+, \mathrm{K}+$-ATPase pump gene ATP1A2 associated with familial hemiplegic migraine and benign familial infantile convulsions. Ann Neurol 2003;54:360-366.

14. Kraus RL, Sinnegger MJ, Koschak A, et al. Three new familial hemiplegic migraine mutants affect P/Q-type Ca2+ channel kinetics. J Biol Chem 2000;13:92399243.

15. Koenderink JB, Zifarelli G, Qiu LY, et al. Na,KATPase mutations in familial hemiplegic migraine lead to functional inactivation. Biochim Biophys Acta 2005; 1669:61-68.
16. Vanmokot KRJ, Kors EE, Turk U, et al. Two de novo mutations in the Na,K-ATPase gene ATP1A2 associated with pure familial hemiplegic migraine. Eur J Hum Genet 2006;14:555-560.

17. Vanmolkot KRJ, Babini E, De Vries B, et al. The novel L1649Q mutation in the SCN1A epilepsy gene is associated with familial hemiplegic migraine: genetic and functional studies. Hum Mutat 2007;28:522.

18. Haan J, Terwindt GM, Ophoff RA, Frants RR, Ferrari MD. Is familial hemiplegic migraine the hereditary form of basilar artery migraine? Cephalalgia 1995;15: 477-481.

19. Black DF. Sporadic hemiplegic migraine. Curr Pain Headache Rep 2004;8:233-238.

20. Thomsen LL, Olesen J. Sporadic hemiplegic migraine. Cephalalgia 2004;24:1016-1023.

21. Carrera P, Piatti M, Stenirri S, et al. Genetic heterogeneity in Italian families with familial hemiplegic migraine. Neurology 1999;13:26-33.

22. Ducros A, Joutel A, Vahedi K, et al. Mapping of a second locus for familial hemiplegic migraine to 1q21-q23 and evidence for further heterogeneity. Ann Neurol 1997;42:885-890

23. Gardner K, Barmada M, Ptacek L, et al. A new locus for hemiplegic migraine maps to chromosome 1q31. Neurology 1997;49:1231-1238.

24. Riant F, De Fusco M, Aridon P, et al. ATP1A2 mutations in 11 families with familial hemiplegic migraine. Hum Mutat 2005;26:281.

25. Thomsen LL, Ostergaard E, Romer SF, et al. Sporadic hemiplegic migraine is an aetiologically heterogeneous disorder. Cephalalgia 2003;23:921-928.

26. Ferrari MD, Goadsby PJ. Migraine as a cerebral ionopathy with abnormal central sensory processing. In: Gilman S, Pedley T, eds. Neurobiology of disease. New York: Elsevier, 2006:333-348.

27. May A, Ophoff RA, Terwindt GM, et al. Familial hemiplegic migraine locus on $19 \mathrm{p} 13$ is involved in the common forms of migraine with and without aura. Hum Genet 1995;96:604-608.

28. Terwindt GM, Ophoff RA, van Eijk R, et al. Involvement of the CACNA1A gene containing region on 19p13 in migraine with and without aura. Dutch Migraine Genetics Research Group. Neurology 2001;56: 1028-1032.

29. Moskowitz MA, Bolay H, Dalkara T. Deciphering migraine mechanisms: clues from familial hemiplegic migraine genotypes. Ann Neurol 2004;55:276-280. 